\title{
CSWB: Where complexity serves simple ideals
}

\author{
Norman E. Taylor*
}

In the two years since we published the first full issue of our Journal, the embrace of collaborative approaches to achieving community safety and well-being has continued to advance rapidly and broadly. This is welcome news unfolding against a backdrop of global events and trends that carry potential implications for public policy and system capacity at every jurisdictional level, down to local communities. If the wider socio-economic factors that contribute to marginalization, service equity gaps, and their attendant social symptoms have not worsened in the past two years, certainly neither have we seen much in the way of encouragement that the complex challenges facing a great many of our fellow citizens are going to ease up anytime soon.

\section{OUR SPECIAL RE-LAUNCH ISSUE}

Thus, the essential mission of this still relatively new open access journal has also grown, both in its urgent importance and in its scope. During this same period, the Journal's champions have successfully tested the waters through the publication of a diverse mix of over 40 articles, across six issues, featuring original research, social innovation, and commentary that reflect a wide spectrum of disciplines. We are pleased to announce, through this special issue, the reintroduction of the Journal of CSWB as it now enters its full and continuing production mode.

Thanks are due to the Board of Directors of the Community Safety Knowledge Alliance (CSKA), our parent organization, for their original vision and continuing support for the Journal. But even more, we owe our early success and our promising future to the many authors whose contributions have given proof to the Journal's founding premise. To wit, "... we must invent the means to travel from research, to practice, to the ultimate alignment of the systems that are intended to serve society. ... together, we can discover, invent, and with the clarity of social science to guide us, we might just change the way we all do business." (Taylor, 2016)

\section{SEEKING A NEW FRAME}

So experimental was the launch of the Journal two years ago that, in developing our initial editorial sections, there was no template or model available for organizing our still-forming concepts of what "CSWB" might ultimately include. In hindsight, we may have adopted a structure that was much more complicated than we need it to be. Certainly, any field of endeavour that claims to embrace multiple social science disciplines, and to both draw upon and serve multiple sectors of public services, must by definition be complex in its scope. Our list of potential topics and our range of cross-cutting themes are vast, and our aim must continue to be as wide and inclusive as possible as we seek to attract our contributors and our readers alike. But, such complexity does little to help us convey the essence of our Journal in any sort of 'elevator pitch'. And, moreover, if our aim is also to integrate multisector and multi-disciplinary efforts under some common cause, it is important that any construct we adopt does not serve to further fragment those efforts.

And so, as we prepared to re-launch our Journal's ongoing production phase, we have reflected on several years of conversation with collaborative human services innovators and adopters, on current and emerging policies and practices, and on the growing body of literature and evidence-based scholarship that is variously underpinning, critiquing, and all the while attempting to give clearer definition to these and other closely related practices in Canada and abroad. We discovered that, whether consciously naming their efforts as CSWB (as is more familiar today across Canada and in parts of the USA), or focused on the interfaces among policing, justice, and public health (as in the Law Enforcement Public Health (LEPH) movement that has taken root more strongly in Australia and in parts of Europe), like-minded researchers and practitioners are indeed reflecting a lot of common cause.

We set ourselves a challenge: to find a way to express what this cause is all about in just a few key words. We settled on four words that in our view express the framing ideals of CSWB with some degree of elegance; that is to say, none can be taken alone, and each ideal is integral to the others. The four words are Trust, Strengths, Services, and Justice. These are the four new intersecting sections that will shape and guide the editorial thrust of our Journal as we move forward. Figure 1 depicts these four central ideals, adds some level of depth to each, and also shows the more complex array of cross-cutting themes and topics that sit below, to inform all of them together.

Time will tell if better words or some other structure might reveal itself, and we will no doubt continue to learn more about how these concepts intersect and build upon one another in service of greater understanding and collective impact. For the foreseeable future, our articles will be assembled under these four principal sections. We will continue to extend our open invitation to scholars, policy-makers, and

Correspondence to: Norman E. Taylor, Journal of Community Safety and Well Being, Community Safety Knowledge Alliance (CSKA), 111 Research Drive, Suite 105, Saskatoon, SK S7N 3R2.

E-mail: ntaylor@cskacanada.ca 


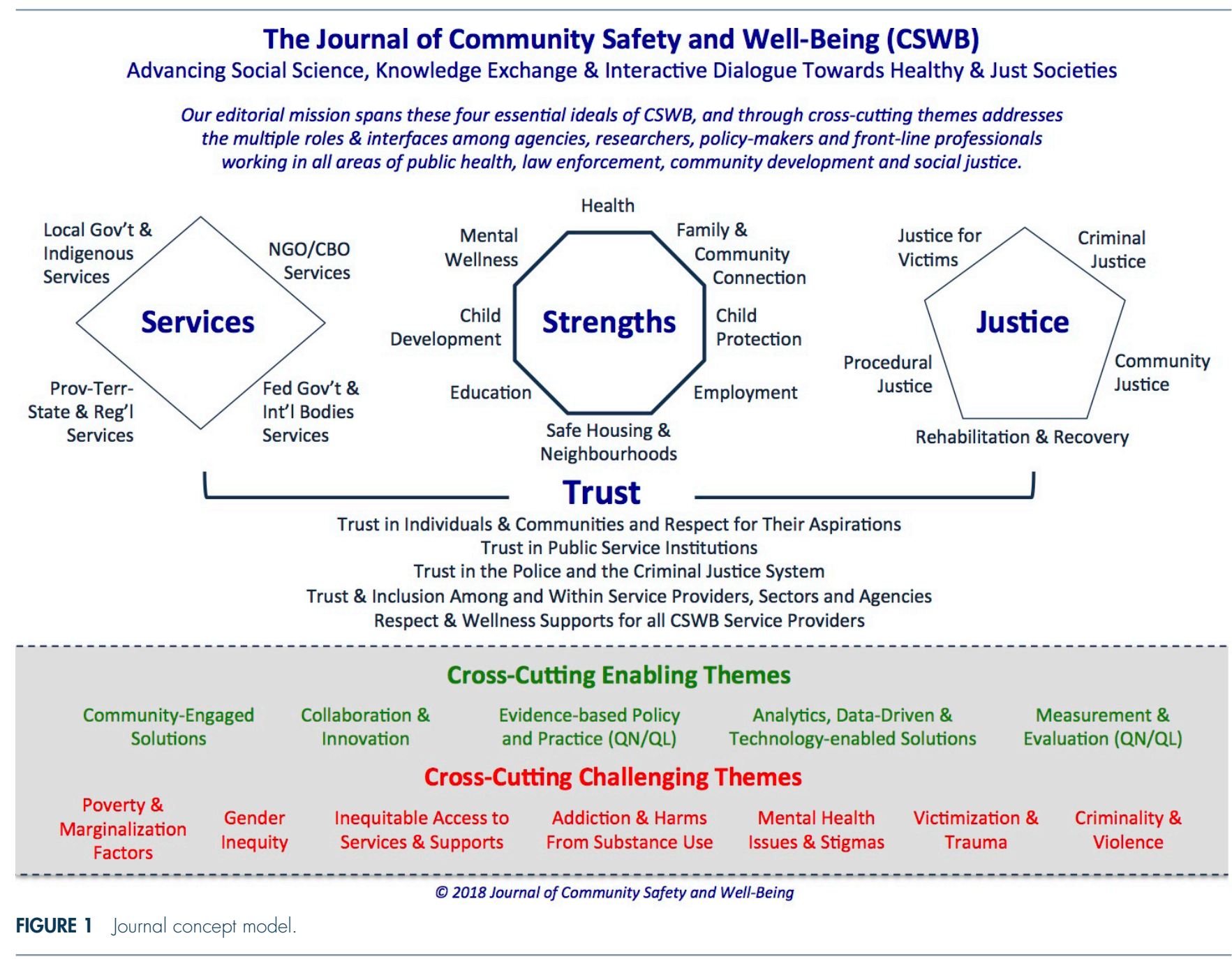

practitioners to consider if your work, your studies, and your search for better ways of doing business might align with any one of these words, or with all of these words together. If so, we invite you to consider the potential of your work to inform and stimulate others who may be pursuing similar ambitions.

I am pleased and very proud to introduce our exemplary panel of Section Editors (see sidebar) who will be working to encourage and support us all through these article identification, peer review, and publication processes. Note that each has contributed some introductory thoughts tied to their respective sections as Commentaries that form the basis of this special re-launch issue of the Journal. As well, each is already working hard to expand our multi-sector sources of contributing authors, while also continuing to grow our slate of qualified academic and practice-based peer reviewers in every related discipline.

\section{LOOKING AHEAD: PARTNERSHIPS EXPAND AND STRENGTHEN OUR GLOBAL COMMUNITY}

In Volume 2(3) of the Journal, Crofts and Thomas (2017) introduced early plans that were then underway to bring the Fourth International Law Enforcement Public Health conference to Toronto in October of this year. I am pleased to report that this conference is shaping up to be another success for the global LEPH community, and also as a timely event that should interest every CSWB practitioner, policy-maker or researcher in Canada and the USA. To top it off, our Journal has joined together with the conference organizers to provide an ideal and sought-after publishing venue for many of the event's highest impact features, and to serve as a continuing venue for the global LEPH research and practice community.

Dozens of LEPH papers have already been put forward for consideration, and our editorial team is currently selecting several for publication in both our early fall issue (October) and in our year-end issue (December) that will be themed to the conference proceedings and outcomes. Both of these issues will also feature a number of other high-quality general submissions that we have received throughout 2018. More information on the upcoming LEPH Conference in Toronto can be found at https://leph2018toronto.com

As we welcome the global LEPH community into our Journal, we are also pleased to feature one additional Commentary article in this special re-launch issue, alongside those from our Section Editors. This paper, by Australian doctoral candidate Melissa Jardine, addresses the important issue 


\section{OUR EDITORIAL TEAM}

\section{Dr. Nick Crofts, Section Editor - Services}

School of Population and Global Health, University of Melbourne, Australia

Center for Law Enforcement Public Health, Melbourne, Australia

Mobilizing, aligning, improving, and validating through evidence, the services, programs, policies and capacities of the broader human services, justice and public health systems.

\section{Dr. Katy Kamkar, Section Editor - Trust}

Clinical Psychologist, Centre for Addiction and Mental Health (CAMH), Toronto, Canada Assistant Professor, Department of Psychiatry, University of Toronto

Director - Badge of Life Canada (BOLC)

Collaborative Centre for Justice and Safety (CCJS) Advisory Council

Ensuring trust, wellness and inclusion among police, all human service providers, and their governing authorities, while continuously cultivating and affirming trust with those they collectively aim to serve.

\section{Dr. Rick Linden, Section Editor - Justice}

Chair, Manitoba Police Commission, Winnipeg, Canada

Professor of Sociology, University of Manitoba, Winnipeg, Canada

Director, Community Safety Knowledge Alliance (CSKA), Saskatoon, Canada

Support and reconciliation for society, communities, families, adults and children recovering from victimization, criminality, and other socio-economic harms, while ensuring public confidence, effectiveness and efficiency in the operations, staffing, training and leadership of the policing, corrections and criminal justice systems.

\section{Dr. Brian Rector, Section Editor - Strengths}

Executive Director, Research and Evidence Based Excellence,

Saskatchewan Ministry of Justice and Ministry of Social Services, Regina, Canada

Working together with individuals, families, communities and cultures to improve life quality, to build strength-based capacities, and to achieve social outcomes through innovative, data-driven analysis and measurable solutions. of gender inclusion in law enforcement. It not only informs public health approaches, but also provides another timely tie-in to some priority research of the Canadian Association of Chiefs of Police (CACP), whose Executive Global Studies 2018 program is just this month issuing its report and forward actions arising from its 17-country study into Authentic Inclusion in workplaces. We hope to build upon that work in future issues of the Journal.

Finally, this past April the CACP partnered with the Saskatchewan Government, the Saskatoon Police Service and others to execute a first-of-its-kind conference dedicated to emerging applications of Open Analytics in CSWB. Section Editor Dr. Brian Rector played a leadership role in bringing about this conference, during which almost 200 delegates shared their early experiences in data-driven programming and policy. The Journal looks forward to continued work with the conference partners to bring further attention to these multi-sector data analytics models, their early impacts on practice, their policy challenges, and their ultimate outcomes on community safety and well-being.

On behalf of our new Editorial Team, our governing body at CSKA, and our publishing team at Multi-med, I thank you for your patience as we have proceeded through this transition to our production model. We look forward to delivering to you a rich mixture of articles and dialogue that touch on a wide range of themes and topics of urgency, framed under four simple, but compelling, ideals.

CONFLICT OF INTEREST DISCLOSURES

The author declares no conflicts of interest.

\section{AUTHOR AFFILIATIONS}

*Editor-in-Chief, Journal of Community Safety and Well Being.

\section{REFERENCES}

Crofts, N. \& Thomas, S. (2017). Law enforcement and public health: finding common ground and global solutions to disparities in health and access to criminal justice. Journal of Community Safety and Well-being, 2(3).

Taylor, N.E. (2016). Your invitation to a new partnership in discovery and invention [editorial]. Journal of Community Safety and Well-being, 1(1), 1-2. 